\title{
Patient-reported outcomes after incisional hernia repair
}

\author{
N. van Veenendaal ${ }^{1}$ - M. M. Poelman² ${ }^{2}$ B. van den Heuvel $^{3}$ - B. J. Dwars ${ }^{4}$. W. H. Schreurs ${ }^{5}$. J. H. M. B. Stoot ${ }^{6}$. \\ H. J. Bonjer ${ }^{1}$
}

Received: 10 March 2021 / Accepted: 29 June 2021 / Published online: 2 August 2021

(c) The Author(s) 2021

\begin{abstract}
Purpose Patient-reported outcomes (PROs) are pivotal to evaluate the efficacy of surgical management. Debate persists on the optimal surgical technique to repair incisional hernias. Assessment of PROs can guide the selection of the best management of patients with incisional hernias. The objective of this cohort study was to present the PROs after incisional hernia repair at long term follow-up.

Methods Patients with a history of incisional hernia repair were seen at the out-patient clinic to collect PROs. Patients were asked about the preoperative indication for repair and postoperative symptoms, such as pain, feelings of discomfort, and bulging of the abdominal wall. Additionally, degree of satisfaction was asked and Carolina Comfort Scales were completed. Results Two hundred and ten patients after incisional hernia repair were included with a median follow-up of 3.2 years. The main indication for incisional hernia repair was the presence of a bulge (60\%). Other main reasons for repair were pain (19\%) or discomfort (5\%). One hundred and thirty-two patients (63\%) reported that the overall status of their abdominal wall had improved after the operation. Postoperative symptoms were reported by 133 patients (63\%), such as feelings of discomfort, pain and bulging. Twenty percent of patients reported that the overall status of their abdominal wall was the same, and $17 \%$ reported a worse status, compared to before the operation. Ten percent of the patients would not opt for operation in hindsight. Conclusion This study showed that a majority of the patients after incisional hernia repair still report pain or symptoms such as feelings of discomfort, pain, and bulging of the abdominal wall 3 years after surgery. Embedding patients' expectations and PROs in the preoperative counseling discussion is needed to improve decision-making in incisional hernia surgery.
\end{abstract}

Keywords Incisional hernia $\cdot$ Ventral hernia $\cdot$ Quality of life $\cdot$ Patient-centered outcomes $\cdot$ Patient-reported outcomes

\section{Introduction}

N. van Veenendaal

n.vanveenendaal@amsterdamumc.nl

1 Department of Surgery, Amsterdam University Medical Center, Boelelaan 1117, 1081 HV Amsterdam, The Netherlands

2 Department of Surgery, Sint Franciscus Gasthuis, Rotterdam, The Netherlands

3 Department of Surgery, Radboud University Medical Center, Nijmegen, The Netherlands

4 Department of Surgery, Slotervaart Medical Center, Amsterdam, The Netherlands

5 Department of Surgery, Noordwest Ziekenhuisgroep, Alkmaar, The Netherlands

6 Department of Surgery, Zuyderland Medical Center, Sittard/Heerlen, The Netherlands
Patients who develop incisional hernias have a reduced overall quality of life (QoL) because of the impact of incisional hernias on physical functioning and role functioning $[1,2]$. Finally, $73-80 \%$ of patients require surgical repair $[2,3]$. Reported success rates for incisional hernia repair vary considerably, depending on the primary outcome and the definition of a 'successful' incisional hernia repair. Whereas surgery-specific outcomes such as recurrence and complication rates are improving, a significant proportion of incisional hernia repairs are performed for symptom relief and to improve the QoL of the patient. The importance and hierarchy of surgical outcomes are subject to discussion [4].

In the last decade, the focus in hernia research has shifted from surgical outcomes, such as recurrences and complications, to patient-centered outcomes. Currently, outcomes such as chronic pain and QoL are frequently used as primary 
outcomes [5-7]. Since the goal of elective surgical interventions is to improve health-related QoL, measuring these patient-centered outcomes is of utmost importance [8].

Several instruments are used to measure QoL after incisional hernia repair [9]. Besides, an increasing number of organizations are collecting and assessing patient-reported outcomes (PROs). The concept of PROs serves to evaluate patients' point of view on outcomes [10]. The success of incisional hernia repair can be determined by adhering to the patient's PROs.

Currently, there is no standardization of PROs in incisional hernia surgery and methodological quality of QoL instruments is poor [11]. Despite the increased emphasis on PROs in incisional hernia surgery, the correlation of PROs with preoperative indications and expectations is lacking. We aimed to elucidate preoperative expectations and compare them with postoperative PROs in incisional hernia patients.

\section{Methods}

Patients were recruited from the multicenter prospective cohort study: the PINCH-Phone [12]. In short, the objective of the PINCH-Phone study was to develop and evaluate a new screening method for recurrent incisional hernias. Participants were asked questions by phone and underwent a physical examination at the out-patient clinic approximately 4 weeks after the phone call.

For this study, participants were invited to the out-patient clinic, and were retrospectively asked about the indication for their incisional hernia repair and prospectively interviewed about the postoperative PROs. Approval for this study was obtained from the Medical Ethical Committee of all participating hospitals in the Netherlands: Medical Center Alkmaar, Slotervaart Medical Center, VU University
Medical Center, Zuyderland Medical Center Sittard/Heerlen. The STROBE guidelines were used to report this study [13].

Medical records of patients who had an operation code for 'incisional hernia repair' between January 2012 and December 2015 were screened. Patients with primary and recurrent incisional hernias were included. Patients with a history of complex abdominal wall treatment, presence of an ostomy, insufficient understanding of the Dutch language, or a mental disorder were not included in this study.

The interview questions are listed in Table 1 . The interview took place at the out-patient clinic and lasted approximately $15 \mathrm{~min}$. All interviews were carried out by one researcher, who was not involved with patient care, and not responsible for the healthcare-related consequences of the outcomes.

Specifics of the incisional hernia and details of the method of repair were obtained from patients' files.

The primary outcome of this study was the PROs on satisfaction and current status after incisional hernia repair. Secondary outcomes were the indication for repair and QoL scores, according to the Carolina Comfort Scale (CCS). The CCS is a validated, disease-specific questionnaire for patients after incisional hernia repair [14]. The CCS contains 23 items measuring the severity of pain, mesh sensation, and mobility impairment caused by the mesh for eight different movements: lying down, bending over, sitting up, activities of daily living, coughing or taking a deep breath, walking, walking the stairs, and exercise. The answers are recorded on a 6-point Likert scale, with 0 being an absence of symptoms to 5 being experiencing disabling symptoms. The CCS score is derived by the sum of all 23 items, with the best possible score being 0 , and the worst possible score being 115 . Symptom aggregates can be calculated as overall pain, mesh sensation, and movement limitation by taking the sum of all scores among all activities for the corresponding symptom. The maximum scores of each QoL domain were compared and a patient was considered symptomatic if the score exceeded $1[14,15]$. The CCS has been proven to be

Table 1 Questions of the patient-reported outcomes' measurement

$\begin{array}{ll}\begin{array}{c}\text { Indication for surgery } \\ 1\end{array} & \text { What was the indication for your hernia repair? } \\ \begin{array}{c}\text { Satisfaction with surgery } \\ 2\end{array} & \begin{array}{c}\text { Considering the overall status of your abdominal wall, at the site of your incisional hernia repair: is it better, the } \\ \text { same or worse after the operation? }\end{array} \\ 3 & \text { Knowing the result of your incisional hernia repair, would you undergo the same procedure for an incisional hernia? } \\ \text { Current status } & \text { Do you have any symptoms at the site of your incisional hernia repair? If yes, what are your symptoms? } \\ 4 & \text { Have you noticed anything at the site of your incisional hernia repair? If yes, what have you noticed? } \\ 6 & \text { Have you noticed something at the site of your incisional hernia repair when coughing, sneezing, or squeezing? } \\ 7 & \text { Could you please stand up and put one hand flat at the site of your incisional hernia repair. Put the other hand to } \\ & \text { your mouth and blow. Do you feel anything at the site of your incisional hernia repair? }\end{array}$


valuable in hernia research and has been validated for the Dutch language [16].

Finally, physical examination was performed to check all patients for recurrences of the incisional hernia. A recurrence was defined as: 'any abdominal wall gap with or without a bulge in the area of a postoperative scar, palpable or perceptible by clinical examination or imaging' $[17,18]$. Physical examination was performed both in standing and supine position. In case of doubt, an ultrasound was made. Specifics of the incisional hernia and details of the method of repair were obtained from patients' files.

\section{Statistical analysis}

Patient demographics were reported for the total cohort. Additionally, a subanalysis was done to study any differences in baseline characteristics between patients that went for open or laparoscopic repair. Descriptive statistics were reported as means with corresponding standard deviations for continuous variables and percentages for categorical variables. Categorical variables were evaluated using Pearson's chi-squared test and Fisher's exact test when appropriate. Pearson correlation coefficients were utilized to estimate the correlation between different postoperative PROs. Correlations were considered 'strong' if the coefficient value lied between 0.50 and 1 , were said to be 'moderate' if the value lied between 0.30 and 0.49 ; and were considered 'weak' correlations if the coefficient lied below 0.29. A $p$ value of $<0.05$ was considered statistically significant. SPSS software version 23.0 was used to conduct all statistical analyses.

\section{Results}

Medical records of 779 patients were screened and 621 patients were eligible for the study. These patients were sent patient trial information, and of these, 240 (39\%) patients returned the informed consent forms. Nineteen patients could not be reached by telephone. Due to logistical matters, 11 patients could not make it for a hospital visit. Finally, 210 patients visited the out-patient clinic and underwent an indepth interview, between January 2016 and December 2016.

\section{Baseline}

The study population consisted of 105 males (50\%) and 105 females (50\%). The median age at operation was 58.4 years (range 20-93) and BMI $29.8 \mathrm{~kg} / \mathrm{m}^{2}$ (range 17.7-53.1). The mean interval between index hernia repair and enrollment in the study was 38 months (range 12-49). Ninty-nine patients (47.1\%) had undergone laparoscopic incisional hernia repair, and 111 patients $(52.9 \%)$ had undergone conventional open repair. In the open repair group, 94 patients (84.7\%) underwent mesh repair and 17 patients $(15.3 \%)$ non-mesh, suture repair (Table 2).

Respondent and non-respondent characteristics were compared and found to be similar in terms of age, sex, hernia type, and repair techniques. The non-responder group of 411 patients consisted of $44 \%$ men. The median age of the 411 non-responders was 59 years (range 24-93). Sixty-two percent underwent an open repair and 38\% a laparoscopic repair.

\begin{tabular}{lllll}
\hline & Total & Open repair & Laparoscopic repair & $p$ value \\
\hline$N$ & 210 & 111 & 99 & \\
Sex (female) & $105(50 \%)$ & $52(46.8 \%)$ & $53(53.3 \%)$ & 0.33 \\
Age at operation, mean (SD) & $58(13)$ & $58(14)$ & $59(11)$ & 0.51 \\
BMI in kg/m ${ }^{2}$, mean (SD) & $29.8(5.7)$ & $28.7(4.8)$ & $31(6.3)$ & 0.002 \\
Hernia frequency & & & & \\
$\quad$ Primary incisional hernia repair & $154(73 \%)$ & $86(77 \%)$ & $68(69 \%)$ & 0.15 \\
$\quad$ Recurrent incisional hernia repair & $56(27 \%)$ & $25(23 \%)$ & $31(31 \%)$ & $<0.001$ \\
Placement of mesh & & & & \\
$\quad$ No mesh & $18(8.6 \%)$ & $17(15.3 \%)$ & $1(1.0 \%)$ & 0.82 \\
$\quad$ Mesh & $192(91.4 \%)$ & $94(84.7 \%)$ & $98(99 \%)$ & \\
Hernia classification & & & & \\
$\quad$ W1 $(<4 \mathrm{~cm})$ & $78(37.1 \%)$ & $40(36 \%)$ & $38(38.4 \%)$ & 0.003 \\
$\quad$ W2 $(4-10 \mathrm{~cm})$ & $90(42.9 \%)$ & $47(42.3 \%)$ & $43(43.4 \%)$ & $18(18.2 \%)$ \\
$\quad$ W3 (> 10 cm) & $42(20 \%)$ & $24(21.6 \%)$ & $35(26,42)$ & \\
Interval from operation until visit to & $38(27,45)$ & $40(29,48)$ & & \\
$\quad$ out-patient clinic, months (IQR) & & & & \\
\hline
\end{tabular}


Table 3 Indications for incisional hernia repair according to patients

\begin{tabular}{llll}
\hline & $\begin{array}{l}\text { Primary raison for } \\
\text { repair }\end{array}$ & $\begin{array}{l}\text { Secondary reasons for } \\
\text { repair }\end{array}$ & Total times mentioned \\
\hline Presence of a bulge & $124(60 \%)$ & $52(19 \%)$ & $176(37 \%)$ \\
Pain & $40(19 \%)$ & $45(17 \%)$ & $85(18 \%)$ \\
Discomfort & $11(5 \%)$ & $137(51 \%)$ & $148(31 \%)$ \\
Episodes of incarceration & $3(1 \%)$ & $7(3 \%)$ & $10(2 \%)$ \\
Aesthetic & $3(1 \%)$ & $20(7 \%)$ & $23(5 \%)$ \\
Recurrence & $7(3 \%)$ & $3(1 \%)$ & $10(2 \%)$ \\
Acute incarceration & $7(3 \%)$ & - & $7(1 \%)$ \\
Advice of the surgeon & $8(4 \%)$ & $3(1 \%)$ & $11(2 \%)$ \\
Don't know & $7(3 \%)$ & - & $7(1 \%)$ \\
& $210(100 \%)$ & $267(100 \%)$ & $477(100 \%)$ \\
\hline
\end{tabular}

\section{Indication for surgical repair}

Two hundred and three patients $(96.7 \%)$ could recall the indication for incisional hernia repair. One hundred and seventy-two patients mentioned at least two indications, 83 patients reported at least three indications, and 12 patients remembered four indications for surgical repair. Seven patients $(3.3 \%)$ could not remember the reason for incisional hernia repair (Table 3). One hundred and seventy-six patients (84\%) mentioned the presence of a bulge as surgical indication, of which 124 times $(60 \%)$ as primary reason for repair. One hundred and forty-eight patients reported the feelings of discomfort as important indication for surgical repair. Pain was the third indication for repair mentioned by 85 patients, of which 40 times (19\%) reported as primary indication. Other reasons for repair mentioned by patients were aesthetics (5\%), episodes of incarceration (2\%), recurrence $(2 \%)$, advice of the surgeon (2\%), and acute incarceration requiring direct surgical repair $(1 \%)$.

\section{Satisfaction with surgery}

In total, 132 patients (63\%) thought that the overall status of their abdominal wall was better than before the operation. Seventy-eight patients (37\%) reported that either the overall status of their abdominal wall was the same or worse than before the operation (Table 4). Additionally, 188 patients $(90 \%)$ said that they would opt for an operation again. In total, 22 patients (10\%) said that they would not opt for an operation again.

\section{Current status/PROs}

One hundred and thirty-seven patients $(65.2 \%)$ answered 'yes' to one or more questions of the PINCH-Phone [12]. Eighty-nine patients (42\%) reported symptoms 3 years after incisional hernia repair (Table 5). Although 121 patients reported negatively to the question whether they had any
Table 4 Satisfaction after incisional hernia surgery

\begin{tabular}{ll}
\hline Question & Total $(n=210)$ \\
\hline $\begin{array}{l}\text { Overall status of the abdominal wall compared with the situation } \\
\text { before the repair? }\end{array}$ & $132(63 \%)$ \\
Better & $42(20 \%)$ \\
Similar & $36(17 \%)$ \\
Worse & $188(90 \%)$ \\
Would you undergo an incisional hernia repair again? & \\
Yes & $22(10 \%)$ \\
No &
\end{tabular}

Table 5 Reponses from participants on the current status of their abdominal wall

\begin{tabular}{ll}
\hline Question & Total $(n=210)$ \\
\hline Do you have symptoms related to surgical site? & \\
Yes & $89(42 \%)$ \\
No, but & $44(21 \%)$ \\
No & $77(37 \%)$ \\
\hline
\end{tabular}

symptoms, 44 patients did use the open field to specify the symptoms they had. In total, 133 patients $(63 \%)$ reported 184 symptoms. Symptoms reported were feelings of discomfort (30\%), mild but bothersome pain $(21 \%)$, bulging (13\%), severe pain/pain in rest (12\%), pain during exercise only (7\%), abdominal complaints (4\%), and aesthetic complaints (1\%) (Table 6). Seventy-seven patients (36.7\%) had no symptoms.

\section{Carolinas Comfort Scale}

All 192 patients with a mesh completed the CCS at the outpatient clinic. The CCS was missing for 17 patients with open non-mesh repair and for one patient in the laparoscopic group. Mean CCS score was 9.48 (range 0-83), of 
Table 6 Symptoms related to the site of the incisional hernia repair reported by patients

\begin{tabular}{ll}
\hline Symptoms* & Total $(n=210)$ \\
\hline Presence of a bulge & $27(13 \%)$ \\
Severe pain/pain in rest & $26(12 \%)$ \\
Mild but bothersome pain & $45(21 \%)$ \\
Pain at exercise & $13(7 \%)$ \\
Feelings of discomfort & $63(30 \%)$ \\
Abdominal symptoms & $8(4 \%)$ \\
Aesthetic complaints & $2(1 \%)$ \\
\hline
\end{tabular}

*133 patients reporting 184 complaints

Table 7 QoL score by CCS

\begin{tabular}{ll}
\hline Carolina Comfort Scale domain & Total $(n=192)$ \\
\hline Mesh sensation & \\
Mean (SD) & $2.3(5.4)$ \\
Symptomatic patients* & $44(23 \%)$ \\
Pain & \\
Mean (SD) & $4.4(7.1)$ \\
Symptomatic patients & $85(44 \%)$ \\
Activity limitation & \\
Mean (SD) & $2.8(5.8)$ \\
Symptomatic patients & $57(30 \%)$ \\
Cumulative CCS score & \\
Mean (SD) & $9.5(15.5)$ \\
Symptomatic patients & $101(53 \%)$ \\
\hline
\end{tabular}

*Total scores exceeding 1 were considered symptomatic (ranging from 'mild but bothersome' to 'disabling' symptoms)

which 52.6\% $(p=0.32)$ were considered to be symptomatic. According to the CCS, 44\% patients had 'mild but bothersome' to 'disabling' pain (Table 7).

\section{Physical examination}

A clinical recurrence was found in 34 patients (16\%): 14 in the open group and 20 in the laparoscopic group. Fifty-four patients (54\%) that had underwent laparoscopic incisional hernia repair suffered from bulging.

\section{Correlations}

Preoperative pain was moderately correlated with postoperative symptoms, $r(48)=0.310, p=<0.001$. The presence of a postoperative bulge was moderately correlated with satisfaction regarding the status of the abdominal wall, $r$ $(127)=0.395, p=<0.001$. The different postoperative outcomes as reported by patients showed no correlation with the decision to undergo the same operation again. Severe pain as reported by patients was weakly correlated with higher scores on the CCS, $r(22)=0.319, p=<0.001$. Pearson correlation coefficients were weak for other various variables (range $r=0.01-0.26$ ) (supplement).

\section{Discussion}

This study showed that $63 \%$ of patients reported symptoms 3 years after incisional hernia repair. Symptoms reported were feelings of discomfort (30\%), mild but bothersome pain $(21 \%)$, bulging $(13 \%)$, pain in rest $(12 \%)$, pain at exercise (7\%), abdominal complaints $(4 \%)$, and aesthetic complaints (1\%). According to the CCS, $44 \%$ patients had 'mild but bothersome' to 'disabling' pain, and 53\% patients were symptomatic. Although a majority of patients was satisfied after the procedure, $37 \%$ experienced a similar or worse overall status of their abdominal wall compared with preoperatively.

Considering the reported indications for incisional hernia repair, the high percentage of persistent symptoms or pain is an unsatisfactory outcome. Patients with incisional hernias seek medical care for various reasons, such as bulging, pain, discomfort, limitation of daily activities, aesthetic complaints, skin problems, or incarceration with or without strangulation of the hernia content [19]. The presence of a bulge and feelings of discomfort were the most common indications for surgical repair in our study cohort. Discomfort is an important reason why patients seek medical care $[13,20,21]$, and thus warrants symptom relief and improvement of QoL after surgery.

Our results contradict the conclusion of a questionnaire among hernia surgeons. The most important indications for repair according to the experts were pain and limitations in daily activities, whereas discomfort and aesthetic complaints were the least valid indications for repair [3]. The discrepancy between our findings and the outcomes of the questionnaire might be the result of the intent of the surgeon to restore an impairment of the abdominal wall and prevent further harm. In contrast, the concern of the patient is an uncomfortable, disfiguring lump. The discrepancy in indications for hernia repair according to patients and surgeons warrants alignment of indications.

As 53\% of patients are considered to be symptomatic at 3 year follow-up, it is disappointing that a better outcome is not forthcoming. Pain was mentioned by $19 \%$ of patients as primary reason for surgical repair, but $44 \%$ of patients suffered from 'mild but bothersome' to 'disabling' pain at time of this study. Knowledge of the chance on postoperative pain should enhance shared decision-making at the outer patient clinic. Furthermore, as pain and discomfort are subjective terms, clear definitions can benefit the indication setting and postoperative evaluation. 
The recurrence rate of $16 \%$ in our study cohort corresponds with incidences in other studies [2]. However, the outcome recurrence is an objective, surgical outcome that is of less interest to patients. There appears to be a mismatch in accepted outcomes between surgeons' and patients' perspectives. The relatively high percentage of bulging found at physical examination can be explained by the fact that brigded repairs without defect closure were performed. Since presence of a bulge was the primary indication for incisional hernia repair in $60 \%$ of the patients, laparoscopic repair seemed to have failed in achieving symptom relief in these patients. After all, patients expecting to get their bulge repaired, still experience the discomfort of a hernia in case of bulging.

The outcomes of this study show the relevance of evaluating PROs after incisional hernia repair, rendering the need of integrating patients' expectations in the preoperative counseling discussion. In the last 2 decades, there has been an increased interest in QoL in surgical research [22-24]. Due to a decrease in recurrence rates in incisional hernia surgery $[25,26]$, the focus has shifted from objective, surgical outcomes to subjective, patient-centered outcomes [9]. In hernia research, PROs have gained importance in the evaluation of surgical outcomes [27, 28]. However, there are still important practical questions about how these outcomes should be collected, visualized, shared, and used to improve the quality of care [11]. Although, we could not identify strong correlations between preoperative indications and postoperative PROs, our results do show discussion points and input for future research to enhance shared decision-making in incisional hernia surgery.

Prior studies have quantified the outcomes after incisional hernia repair with questionnaires selected by surgeons. Hernia-specific tools that are used are the CCS, Activities Assessment Scale (AAS) and Hernia-Related Quality of Life Scale (HerQLes). Furthermore, various general QoL questionnaires are used with hernia-specific questionnaires, or as sole method. The heterogeneity in hernia tools is extensive, and standardization in hernia surgery is warranted [29]. However, before a core outcome set can be defined, questions should be raised on how to best define a successful repair and how to define the parameters for success. A balanced set of outcomes from the patient's and the surgeon's perspective should be developed.

Satisfaction with a surgical procedure is the relation between expectations and experience, and is a major determinant in defining successful repair [30]. The effect of a surgical intervention on QoL influences satisfaction after incisional hernia repair [31]. Although successful repair can be expected in the majority of cases, $15-32 \%$ of the patients after incisional hernia repair will get a recurrence or suffer from chronic pain. These unwanted outcomes are important determinants in the outcomes of incisional hernia repair with its reflection on satisfaction rates. Reasons for dissatisfaction after incisional hernia repair are impairment of physical function, scars, abdominal pain, and a disappointing aesthetic result [32]. Knowledge of expectations and satisfaction rates allows us to optimize shared decision-making in incisional hernia management.

Although our results show that $63 \%$ of the patients were satisfied, 37\% reported that either the status of their abdomen was the same or worse compared to preoperatively. Our findings correspond with the previous studies showing satisfaction rates of 50\%-86\% at 5-10 year follow-up [33-36]. Furthermore, our findings reveal that $90 \%$ of the patients would opt for the operation again. With the knowledge of hindsight, many may wonder if patients would have opted for the operation as they seem to have been exposed to the risks of surgery with no clear benefit.

The CCS was used to quantify QoL after incisional hernia repair. Our results show that $53 \%$ patients can be considered symptomatic. This corresponds with $42 \%$ patients reporting symptoms related to the surgical site. The paindomain of the CCS had the highest mean scores with $44 \%$ patients reporting postoperative pain. This resembles a study in which $38 \%$ of the mesh patients experienced occasional pain at the site of the operated area, $43 \%$ reported moderate immobility of the abdominal wall, and $31 \%$ experienced an unspecified foreign-body sensation [34]. Although the CCS is a disease-specific questionnaire, this questionnaire might not cover all quality-of-life-related complaints of patients.

Incisional hernia research is mostly featuring an ongoing debate regarding open versus laparoscopic surgical management looking at surgical outcomes [37]. Although laparoscopic repair is recommended compared with open repair when considering HRQoL [38], our results showed no difference in PROs between the two groups (data not shown).

This study has several limitations. First, participants were interviewed several years after incisional hernia repair and were asked about postoperative PROs only. Preoperative data were lacking, making a comparison impossible. The presence of prospective preoperative data would have strengthened our study design and is warranted in future research. The need for assessment of pre- and postoperative QoL differences using validated questionnaires has been acknowledged by other authors, as well [11]. With the current focus on PROs as primary outcome, more preoperative data are currently collected using validated questionnaires. It is also recommended to report the level of pre- and postoperative pain to determine the success of an incisional hernia repair. A second limitation is the lack of pre- and postoperative data on the use of analgesics in this study. It could have strengthened the study to have information on analgesics use, and including analgesic consumption in future studies is recommended. Our response rate of $39 \%$ can be considered a third limitation. 
Despite this relatively low response rate, it is still higher than the average $25-30 \%$ when no follow-up or reminder is sent [39]. Of the 621 patients that were approached, a potential bias can be that only patients participated with symptoms, that suffered from postoperative complications or that felt mistreated during their hospital stay. Patients that suffer from complaints are more likely to participate than those who do not have complaints at all [27]. Finally, a limitation of the correlation analysis is that only two variables are explored. Effects of other variables are not taken into account. Furthermore, estimation of the Pearson's correlation coefficient is sensitive to data distribution and is not robust. Outliers might have had their influence on the statistic $r$. Interpretation of the strength of the associations should be considered in light of this lack of robustness.

\section{Conclusion}

Sixty-three percent of patients reported symptoms 3 years after incisional hernia repair, mostly feelings of discomfort, pain, and bulging. Thirty-seven percent of patients experienced a similar or worse status of their abdominal wall compared to preoperatively. Considering the main indications for incisional hernia repair to be presence of a lump and discomfort, the high percentage of symptoms and pain is an unsatisfactory outcome for elective incisional hernia repair. The outcomes of this study show the relevance of evaluating patient-reported outcomes after incisional hernia repair, rendering the need of integrating patients' expectations in the preoperative counseling discussion.

Supplementary Information The online version contains supplementary material available at https://doi.org/10.1007/s10029-021-02477-7.

Funding Not applicable.

\section{Declarations}

Conflict of interest Nadine van Veenendaal, Marijn Poelman, Baukje van den Heuvel, Hermien Schreurs, Jan Stoot, and Jaap Bonjer have no conflict of interest or financial ties to disclose.

Ethical approval Approval for this study was obtained from the Medical Ethical Committee of all participating hospitals in the Netherlands: Medical Center Alkmaar, Slotervaart Medical Center, VU University Medical Center, Zuyderland Medical Center Sittard/Heerlen.

Human and animal rights This article does not contain any studies with human participants or animals performed by any of the authors.

Consent to participate All patients have signed an informed consent declaration agreeing to participate.

Consent for publication All patients have signed an informed consent declaration agreeing that the results of this study would be published.
Open Access This article is licensed under a Creative Commons Attribution 4.0 International License, which permits use, sharing, adaptation, distribution and reproduction in any medium or format, as long as you give appropriate credit to the original author(s) and the source, provide a link to the Creative Commons licence, and indicate if changes were made. The images or other third party material in this article are included in the article's Creative Commons licence, unless indicated otherwise in a credit line to the material. If material is not included in the article's Creative Commons licence and your intended use is not permitted by statutory regulation or exceeds the permitted use, you will need to obtain permission directly from the copyright holder. To view a copy of this licence, visit http://creativecommons.org/licenses/by/4.0/.

\section{References}

1. Cherla DV, Moses ML, Viso CP, Holihan JL, Flores-Gonzalez JR, Kao LS, Ko TC, Liang MK (2018) Impact of abdominal wall hernias and repair on patient quality of life. World J Surg 42:19-25

2. Jensen KK, Emmertsen KJ, Laurberg S, Krarup PM (2020) Longterm impact of incisional hernia on quality of life after colonic cancer resection. Hernia 24(2):265-272

3. Nieuwenhuizen J, Kleinrensink GJ, Hop WC, Jeekel J, Lange JF (2008) Indications for incisional hernia repair: an international questionnaire among hernia surgeons. Hernia 12(3):223-225

4. Guyatt GH, Oxman AD, Kunz R, Vist GE, Falck-Ytter Y, Schünemann HJ, GRADE Working Group (2008) What is "quality of evidence" and why is it important to clinicians? BMJ 336(7651):995-998

5. Mussack T, Ladurner R, Vogel T, Lienemann A, Eder-Willwohl A, Hallfeldt KK (2006) Health-related quality-of-life changes after laparoscopic and open incisional hernia repair: a matched pair analysis. Surg Endosc 20(3):410-413

6. Snijder CW, Graham LA, Vick CC, Gray SH, Finan KR, Hawn MT (2011) Patient satisfaction, chronic pain, and quality of life after elective incisional hernia repair: effects of recurrence and repair technique. Hernia 15(2):123-129

7. Sosin M, Patel KM, Nahabedian MY, Bhanot P (2014) Patientcentered outcomes following laparoscopic ventral hernia repair: a systematic review of the current literature. Am J Surg 208(4):677-684

8. Rogmark P, Petersson U, Bringman S, Ezra E, Osterberg J, Montgomery A (2016) Quality of life and surgical outcome 1 year after open and laparoscopic incisional hernia repair: PROLOVE: a randomized controlled trial. Ann Surg 263(2):244-250

9. Jensen KK, Henriksen NA, Harling H (2014) Standardized measurement of quality of life after incisional hernia repair: a systematic review. Am J Surg 208(3):485-493

10. U.S. Food and Drug Administration (2009) Guidance for industry patient-reported outcome measures: use in medical product development to support labeling claims. Federal register. U.S. Food and Drug Administration

11. Sand $\varnothing$ A, Rosen MJ, Heniford BT, Bisgaard T (2020) Long-term patient-reported outcomes and quality of the evidence in ventral hernia mesh repair: a systematic review. Hernia 24(4):695-705

12. van Veenendaal N, Poelman MM, van den Heuvel B, Dwars BJ, Schreurs WH, Stoot JHMB, Bonjer HJ (2019) The PINCH-Phone: a new screenings method for recurrent incisional hernias. Surg Endosc 33(9):2794-2801

13. Von Elm E, Altman DG, Egger M, Pocock SJ, Gøtzsche PC, Vandenbroucke JP, STROBE Initiative (2007) The Strengthening the Reporting of Observational Studies in Epidemiology (STROBE) statement: guidelines for reporting observational studies. Lancet 370(9596): 1453-1457 
14. Heniford BT, Walters AL, Lincourt AE, Novitsky YW, Hope WW, Kercher KW (2008) Comparison of generic versus specific quality-of-life scales for mesh hernia repairs. J Am Coll Surg 206(4):638-644

15. Heniford BT, Lincourt AE, Walters AL, Colavita PD, Belyansky I, Kercher KW, Sing RF, Augenstein VA (2016) Carolinas Comfort Scale as a measure of hernia repair quality of life: a reappraisal utilizing 3788 international patients. Ann Surg 267(1):171-176

16. Nielsen K, Poelman MM, den Bakker FM, van der Ploeg T, Bonjer HJ, Schreurs WH (2014) Comparison of the Dutch and English versions of the Carolinas Comfort Scale: a specific quality-oflife questionnaire for abdominal hernia repairs with mesh. Hernia 18(4):459-464

17. Korenkov M, Paul A, Sauerland S, Neugebauer E, Arndt M, Chevrel JP, Corcione F, Fingerhut A, Flament JB, Kux M, Matzinger A, Myrvold HE, Rath AM, Simmermacher RK (2001) Classification and surgical treatment of incisional hernia. Results of an expert's meeting. Langebecks Arch Surg 386(1):65-73

18. Muysoms FE, Miserez M, Berrevoet F, Campanelli G, Champault GG, Chelala E, Dietz UA, Eker HH, El Nakadi I, Hauters P, Pascual MH, Hoeferlin A, Klinge U, Montgomery A, Simmermacher RK, Simons MP, Smietański M, Sommeling C, Tollens T, Vierendeels T, Kingsnorth A (2009) Classification of primary and incisional abdominal wall hernias. Hernia 13(4):407-414

19. Van Ramshorst GH, Eker HH, Hop WCJ, Jeekel J, Lange JF (2012) Impact of incisional hernia on health-related quality of life and body image: a prospective cohort study. Am J Surg 204(2):144-150

20. Urbach DR (2005) Measuring quality of life after surgery. Surg Innov 12(2):161-165

21. Wright JG (1999) Outcomes research: what to measure. World J Surg 23(12):1224-1226

22. Velanovich $\mathrm{V}(2001)$ The quality of life studies in general surgical journals. J Am Coll Surg 193(3):288-296

23. Korolija D, Sauerland S, Wood-Dauphinée S, Abbou CC, Eypasch E, Caballero MG, Lumsden MA, Millat B, Monson JR, Nilsson G, Pointner R, Schwenk W, Shamiyeh A, Szold A, Targarona E, Ure B, Neugebauer E (2004) Evaluation of quality of life after laparoscopic surgery: evidence-based guidelines of the European Association for Endoscopic Surgery. Surg Endosc 18(6):879-897

24. Cella D, Riley W, Stone A, Rothrock N, Reeve B, Yount S, Amtmann D, Bode R, Buysse D, Choi S, Cook K, Devellis R, DeWalt D, Fries JF, Gershon R, Hahn EA, Lai JS, Pilkonis P, Revicki D, Rose M, Weinfurt K, Hays R, PROMIS Cooperative Group (2010) The Patient-Reported Outcomes Measurement Information System (PROMIS) developed and tested its first wave of adult selfreported health outcome item banks: 2005-2008. J Clin Epidemiol 63(11):1179-1194

25. Forbes SS, Eskicioglu C, McLeod RS, Okrainec A (2009) Metaanalysis of randomized controlled trials comparing open and laparoscopic ventral and incisional hernia repair with mesh. Br J Surg 96(8):851-858

26. Eker HH, Hansson BM, Buunen M, Janssen IM, Pierik RE, Hop WC, Bonjer HJ, Jeekel J, Lange JF (2013) Laparoscopic vs. open incisional hernia repair: a randomized clinical trial. JAMA Surg 148(3):259-263

27. Baucom RB, Ousley J, Feurer ID, Beveridge GB, Pierce RA, Holzman MD, Sharp KW, Poulose BK (2016) Patient reported outcomes after incisional hernia repair-establishing the ventral hernia recurrence inventory. Am J Surg 212(1):81-88

28. Jairam AP, Wilson M, Steyerberg EW, Jeekel J, Lange JF (2016) Patient reported outcome measurements in the diagnosis of incisional hernia: PROMIS questionnaire, a pilot study. J Surg Res 203(2):378-382

29. Grove TN, Muirhead LJ, Parker SG, Brogden DRL, Mills SC, Kontovounisios C, Windsor ACJ, Warren OJ (2020) Measuring quality of life in patients with abdominal wall hernias: a systematic review of available tools. Hernia. https://doi.org/10.1007/ s10029-020-02210-w (Online ahead of print)

30. Thompson AG, Suñol R (1995) Expectations as determinants of patient satisfaction: concepts, theory and evidence. Int J Qual Health Care 7(2):127-141

31. Krpata DM, Schmotzer BJ, Flocke S, Jin J, Blatnik JA, Ermlich B, Novitsky YW, Rosen MJ (2012) Design and initial implementation of HerQLes: a hernia-related quality-of-life survey to assess abdominal wall function. J Am Coll Surg 215(5):635-642

32. Paul A, Korenkov M, Peters S, Köhler L, Fischer S, Troidl H (1998) Unacceptable results of the Mayo procedure for repair of abdominal incisional hernias. Eur J Surg 164(5):361-367

33. Burger JW, Luijendijk RW, Hop WC, Halm JA, Verdaasdonk EG, Jeekel J (2004) Long-term follow-up of a randomized controlled trial of suture versus mesh repair of incisional hernia. Ann Surg 240(4):578-583 (discussion 583-5)

34. Langer C, Schaper A, Liersch T, Kulle B, Flosman M, Füzesi L, Becker H (2005) Prognosis factors in incisional hernia surgery: 25 years of experience. Hernia 9(1):16-21

35. Poelman MM, Schellekens JF, Langenhorst BL, Schreurs WH (2010) Health-related quality of life in patients treated for incisional hernia with an onlay technique. Hernia 14(3):237-242

36. Liang MK, Clapp M, Li LT, Berger RL, Hicks SC, Awad S (2013) Patient Satisfaction, chronic pain, and functional status following laparoscopic ventral hernia repair. World J Surg 37(3):530-537

37. Zhang Y, Zhou H, Chai Y, Cao C, Jin K, Hu Z (2014) Laparoscopic versus open incisional and ventral hernia repair: a systematic review and meta-analysis. World J Surg 38(9):2233-2240

38. Bittner R, Bain K, Bansal VK, Berrevoet F, Bingener-Casey J, Chen D, Chen J, Chowbey P, Dietz UA, de Beaux A, Ferzli G, Fortelny R, Hoffmann H, Iskander M, Ji Z, Jorgensen LN, Khullar R, Kirchhoff P, Köckerling F, Kukleta J, LeBlanc K, Li J, Lomanto D, Mayer F, Meytes V, Misra M, Morales-Conde S, Niebuhr H, Radvinsky D, Ramshaw B, Ranev D, Reinpold W, Sharma A, Schrittwieser R, Stechemesser B, Sutedja B, Tang J, Warren J, Weyhe D, Wiegering A, Woeste G, Yao Q (2019) Update of guidelines for laparoscopic treatment of ventral and incisional abdominal wall hernias (International Endohernia Society (IEHS)) - part A. Surg Endosc 33(10):3069-3139

39. Yun GW, Trumbo CW (2000) Comparative response to a survey executed by post, e-mail, \& web form. J Comput Mediat Commun 6(1):JCM613

Publisher's Note Springer Nature remains neutral with regard to jurisdictional claims in published maps and institutional affiliations. 